\title{
Miíase furunculóide de localização atípica
}

\section{Furuncular myiasis in atipic localization}

\author{
Roberta V. Nunes ${ }^{1}$, Adriana C. P. Ferraz², Bárbara de Q. Gadelha ${ }^{3}$, Valéria M. Aguiar Coelho4, \\ Cláudia S. S. Lessa ${ }^{4}$
}

\begin{abstract}
RESUMO
Paciente do sexo feminino de 63 anos, melanoderma, ingressou em hospital público se queixando de prurido e secreção nos glúteos por aproximadamente um mês, após visita em área rural. A mesma relatou que fazia uso de antibiótico pomada recomendado para tratamento de furúnculo. Ao exame clínico observou-se duas lesões hiperêmicas e com exsudato purulento, diagnosticadas como miíase furunculóide. Foi removida uma larva viva de Dermatobia hominis de cada lesão, com auxílio de curativo oclusivo com vaselina e pinça. Três doenças devem ser diferenciadas: furúnculo, miíase furunculóide, (causada por D. hominis) e miíase tecidual (causada por Cochliomyia hominivorax), devido à extensa destruição tecidual causada por esta última.
\end{abstract}

Palavras-chave: Parasitos. Insetos. Miíase/Humanos.

\section{Introdução}

Miíase é uma dermatose comum nos países tropicais, frequente no meio rural devido à maior proximidade entre o homem e os animais. ${ }^{1}$ No meio urbano, a ocorrência de miíases ocasionadas por Cochliomyia hominivorax (Coquerel, 1858) dá-se pela existência de cães errantes que geralmente apresentam ferimentos cuja secreção e odor atrai moscas. ${ }^{2} \mathrm{Na}$ América do Sul, os agentes etiológicos mais comuns de miíase humana são as larvas de $C$. hominivorax, causadoras da bicheira e as larvas de Dermatobia hominis (Wiedemann, 1819), popularmente conhecida como berne. ${ }^{3}$
Os fatores predisponentes para miíases são dermatites, doenças do sistema circulatório, transtornos psiquiátricos, etilismo, desnutrição, imunodepressão, precários hábitos de higiene corporal, baixo nível de instrução, senilidade e abandono familiar. ${ }^{1-4}$

Miíase furunculosa está associada a temperaturas altas, precipitação abundante, vegetação densa e presença de animais. Em zonas de alta infestação o homem é parasitado com frequência. ${ }^{5}$

Os ovos de $D$. hominis depositados em dípteros foréticos originam larvas que ao emergirem penetram na pele intacta através do folículo piloso provocando miíase nodular cutânea. ${ }^{5} \mathrm{O}$ tratamento consiste na retirada da larva e diagnóstico clínico pela demonstração do agente no tecido.
1. Graduada em Medicina, Universidade Federal do Estado do Rio de Janeiro - UNIRIO

2. Doutoranda em Biologia Animal, Universidade Federal Rural do Rio de Janeiro - UFRRJ

3. Mestranda em Zoologia, Universidade Federal do Estado do Rio de Janeiro - UFRJ

4. Docente da Disciplina de Parasitologia, Universidade Federal do Estado do Rio de Janeiro - UNIRIO
Correspondência: Adriana Cristina Pedroso Ferraz.

Av. Duque de Caxias, 2921. Deodoro, Rio de Janeiro, RJ. Brasil.

Cep: 21615-220. adrianapedroso7@yahoo.com.br

Artigo recebido em 23/04/2008 Aprovado em 20/02/2009 


\section{Relato de Caso}

Em fevereiro de 2007 registrou-se três casos de miíases, sendo um furuncular.

Paciente do sexo feminino, 63 anos, melanoderma, residente no Rio de Janeiro, deu entrada no Hospital Geral do Andaraí (HGA), encaminhada para sala de procedimentos contaminados, onde foi informada e autorizou o Termo de Consentimento Livre e Esclarecido (TCLE), conforme Projeto de Pesquisa aprovado pelo Comitê de Ética da UNIRIO e pelo Centro de Estudos do HGA. A queixa principal foi prurido na região glútea com secreção, há aproximadamente um mês, após visita a zona rural, informando episódios de eliminações fisiológicas próximo a riacho. Bom estado geral e em condições adequadas de higiene corporal. Observou-se em região glútea direita edema discreto e hiperemia próximo às duas lesões de aproximadamente $1,0 \mathrm{~cm}$ e $0,5 \mathrm{~cm}$ de diâmetro com uma larva viva por lesão (Figura 1), e exsudato purulento. Referiu uso prévio de antibiótico para tratamento de furúnculo. Um curativo oclusivo com vaselina foi disposto sobre orifícios da lesão por 40 minutos. Após remoção deste, com auxílio de pinça anatômica retiraram-se as larvas, de 1,5 cm (Figura 2) e 1,2 cm de comprimento, transferidas para recipiente de polietileno contendo serragem esterilizada e encaminhadas ao Laboratório de Estudo de Dípteros da UNIRIO para identificação taxonômica.

\section{Discussão}

Pacientes acometidos por este tipo de miíase relatam incômodo e dor, dependendo da localização, podendo haver infecção secundária com diagnóstico diferencial de furúnculo e piodermite. ${ }^{6}$ Este tipo de miíase acomete normalmente áreas expostas de pessoas que frequentam ou residem em zona rural, assim como trabalhadores com acesso ao hábitat dos dípteros $D$. hominis e de seus foréticos, sendo endêmica em regiões de clima tropical. ${ }^{7}$

A paciente relatou que os sintomas tiveram início aproximadamente 30 dias após a possível infestação em zona rural em período favorável para a biologia do díptero, corroborando com Cramer-Ribeiro ${ }^{8}$ que destacam maior incidência de casos de miíases nos meses com temperaturas e umidade elevadas.

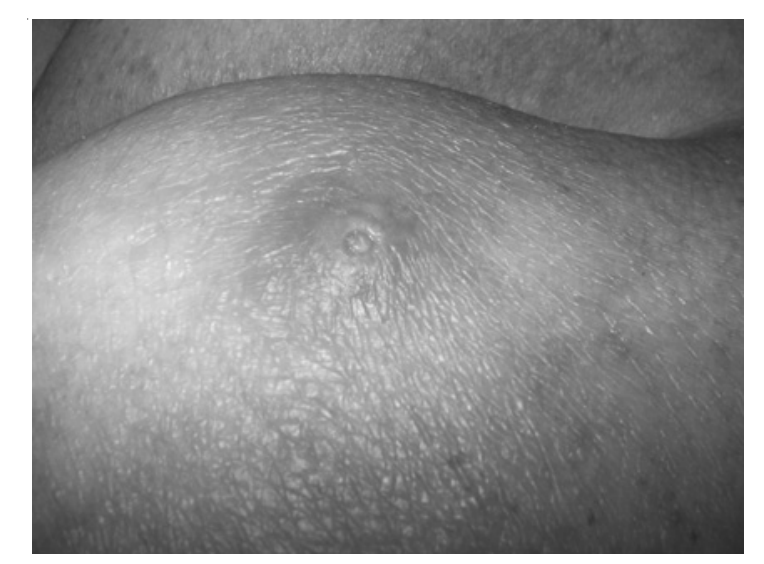

Figura 1: Paciente apresentando larvas de Dermatobia hominis na região glútea.

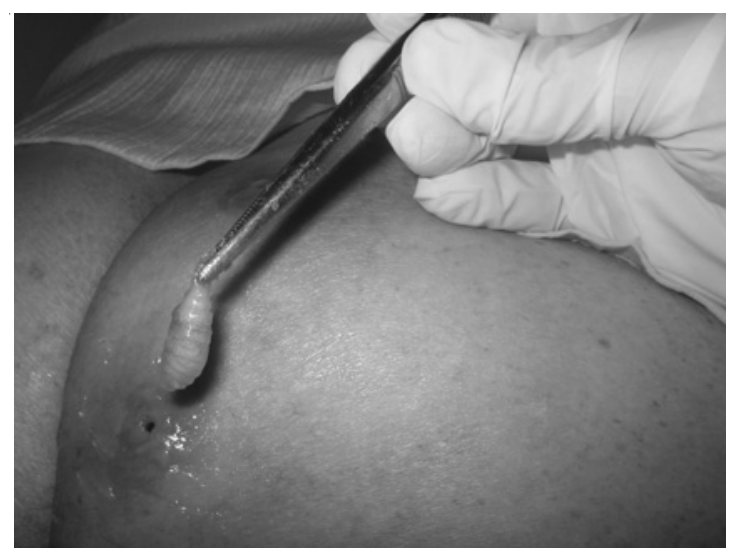

Figura 2: Larva de Dermatobia hominis de $1,5 \mathrm{~cm}$ de comprimento retirada de míase furunculóide .

A miíase nodular cutânea é formada por uma única larva, limitada no folículo piloso, diferente da miíase ocasionada pelas larvas da $C$. hominivorax, onde ocorre uma destruição tecidual muito extensa. Portanto, há necessidade do diagnóstico diferencial destas patologias frequentes em países de clima tropical e neotropical.

\section{Agradecimentos}

Ao Centro de Estudos e funcionários do Hospital Geral do Andaraí e ao apoio financeiro da CAPES, CNPq, UNIRIO e FINEP. 


\begin{abstract}
A 63 year old black female was admitted in a public hospital complaining of itching and secretion in the gluteus for approximately one month after a trip to a rural area. The patient reported using antibiotic ointment for furuncle treatment. At the clinical examination, two hyperemic lesions showing purulent exudate were observed, and were diagnosed as furunculoid myiasis. One Dermatobia hominis larva was removed from each lesion, by means of occlusion using petroleum jelly and tweezers. Three diseases should be differentiated when dealing with this kind of occurrence: furuncles, furunculoid myiasis (caused by $D$. hominis) and tissue myiasis (caused by Cochliomyia hominivorax), due to the extensive tissue destruction caused by the latter.
\end{abstract}

Keywords: Parasites. Insects. Myiasis/Humans.

\section{Referenclas Blbllografficas}

1- Martinez CAR, Romanini DGP, Campos AA, Carneiro VPP, Dalbem CAG. Miíase vulvar: relato de caso. Rev Bras Ginecol Obstet. 2003; 25: 1-9.

2. Nascimento EMF, et al. Miíases humanas por Cochliomyia hominivorax (Coquerel, 1858) (Diptera, Calliphoridae) em hospitais públicos na cidade do Recife, Pernambuco, Brasil. Entomol Vect 2005; 12: 37-51.

3- Guimarães JH, Papavero N. Myiasis in man and animals in the Neotropical Region: Bibliografic database. São Paulo: FAPESP; 1999.

4- Sherman RA. Wound myiasis in urban and suburban United States. Arch Intern Med 2000; 160: 2004-14.
5- Moya-Borja GE. Erradicação ou manejo integrado das miíases neotropicais das Américas? Pesq Vet Bras 2003; 23: 131-8.

6- Azulay R \& Azulay D. Dermatologia. Rio de Janeiro: Guanabara Koogan; 1997.

7- Lombardero OJ, Fontana BAJ. La "ura" (Dermatobia hominis) en la provincia de Formosa. Gac Vet 1968; 30: 297-306.

8- Cramer-Ribeiro BC, Sanavria A, Oliveira MQ, Souza FS, Rocco FS, Cardoso PG. Inquérito sobre os casos de miíase por Cochliomyia hominivorax em cães da zona sul do município do Rio de Janeiro no ano 2000. Braz J Vet Res Anim Sci. 2002; 39: 171-5. 